\title{
PANDEMIA DA COVID-19: mediação para entender a espiral economia-saúde
}

\author{
Diego de Oliveira Souza *
}

\begin{abstract}
Este artigo problematiza a relação entre economia e saúde, tomando a pandemia da COVID-19 como mediação. A partir de uma abordagem materialista histórica da realidade, depreendem-se as interfaces da referida relação com base em dados do período da pandemia. Além disso, aborda os impactos da faceta neoliberal do processo de mundialização do capital para a saúde, a consolidação do complexo médico-industrial/financeiro e como este cresce com a COVID-19, e o processo de determinação social da saúde, a partir do qual se esclarece a relação ontologicamente construída entre economia e saúde, com as particularidades percebidas na trama causal da pandemia. Com isso, refuta-se a concepção linear da relação economia-saúde, demonstrando sua dinâmica espiralada.
\end{abstract}

Palavras-Chave: Coronavírus. Complexo Médico-Industrial/Financeiro. Neoliberalismo. Pandemias. Saúde Pública.

\section{INTRODUÇÃO}

A transmissão do novo coronavírus e as doenças que este provoca ganharam alcance global rapidamente, considerando que as primeiras suspeitas, desde Wuhan, na China, ocorreram no final de dezembro de 2019 e, no final de fevereiro de 2020, a doença já estava disseminada mundialmente. Em 11 de março, foi classificada como pandemia pela Organização Mundial da Saúde (FOLHA..., 2020). ${ }^{1}$ A partir disso, eclodiu o debate sobre a relação entre saúde (pela mediação da pandemia) e economia, sobretudo devido aos impactos econômicos provocados pelas medidas de distan-

\footnotetext{
* Universidade Federal de Alagoas (Ufal).

Av. Manoel Severiano Barbosa, s/n, Bom Sucesso. Cep: 57309-005. Arapiraca - Alagoas - Brasil. diego.souza@ arapiraca.ufal.br

http://orcid.org/0000-0002-1103-5474

${ }^{1}$ Vale destacar que se trata da pior da pandemia desde aquelas que assolaram o mundo no início do século XX (como a “gripe espanhola" e varíola). No início de 2021, já existiram mais de 98 milhões de casos, com aproximadamente 2 milhões de óbitos (WORLD HEALTH ORGANIZATION, 2021).
}

ciamento social (em alguns casos, o lockdown²) necessárias à redução da velocidade de transmissão do vírus. A narrativa distópica construída em torno dessa relação é forjada a partir da preocupação em face de alguns resultados econômicos, revelados desde as primeiras fases da pandemia, em 2020.

Esses resultados estão expressos, por exemplo, no comportamento do Produto Interno Bruto (PIB), porquanto as estimativas do Fundo Monetário Internacional (FMI) apontaram contração para diversos países no ano de 2020, refletindo o impacto a curto prazo do aumento acelerado das infecções pelo SARS-CoV-2 (FMI, 2021). Para se ter uma ideia, o PIB da zona do euro teve um encolhimento de $7,2 \%$, seguindo a tendência de queda de países de outras regiões, como Japão $(-5,1 \%)$, Brasil $(-4,5 \%)$ e Estados Unidos da América (EUA)

${ }^{2}$ Esse termo tem sido empregado para caracterizar as me-
didas mais rígidas de confinamento, estabelecendo o blo-
queio rigoroso da circulaçáo de pessoas nas cidades, com
fechamento dos espaços públicos e da maioria dos espaços
privados, exceto serviços considerados essenciais. Termos
como lockdown, distanciamento social (evitar aglomera-
ções), isolamento social (confinamento dos casos suspei-
tos) e outros, oriundos da epidemiologia, passaram a ser
utilizados pelas diversas ciências, na tentativa de decifrar
a complexidade da conjuntura estabelecida.


$(-3,4 \%)$. Mesmo a China, que apresentou crescimento de 2,3\%, desacelerou em relação a 2019, quando seu PIB cresceu 6\%. Por outro lado, após as intervenções estatais com apoio fiscal adicional e o avanço da imunização contra a COVID-19, já se percebe a reação nas projeções para 2021, que calcula um crescimento de 4,2\% na zona do euro, 3,6\% no Brasil, 5,1\% nos EUA e 8,1\% na China (FMI, 2021), contribuindo para nossa premissa de que há uma relação peculiar entre economia e saúde.

Diante dos impactos econômicos, alguns líderes de Estado assumiram um discurso a favor da economia, relativizando a importância do distanciamento social, sob a alegação de que uma bancarrota, seguida do aumento do desemprego, pode ser mais prejudicial à saúde do que o próprio coronavírus. Entre esses, estão, no início da confirmação de casos em seus respectivos países, o ex-primeiro-ministro da Itália, Giuseppe Conte, o ex-presidente dos Estados Unidos, Donald Trump, e o presidente do Brasil, Jair Bolsonaro, que manteve o discurso mesmo depois da ascensão da curva estatística de infectados e mortos. A preocupação com os impactos econômicos ganha cada vez mais espaço, mesmo entre aqueles que defendem o distanciamento social, refletindo-se em todas as áreas, inclusive na própria saúde pública, no que diz respeito ao seu financiamento. Há, portanto, um entendimento linear de que a pandemia deu origem a uma dinâmica econômica caন్ ótica que, se não controlada, se prolongará até a ๙ catástrofe do sistema de saúde. Ou, ainda, que o o futuro da saúde pública está hipotecado à volฮิ ta do crescimento econômico, em uma equação $\exists$ de causa-efeito. Neste sentido, apresentamos ¿ este estudo teórico com o objetivo de refutar o लं pensamento linear, trazendo uma reflexão que

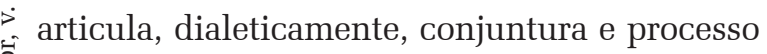
histórico, o que pode contribuir para desvelar a real relação estabelecida entre economia e saúde, tomando a pandemia da COVID-19 como mediação analítica.

Partimos de uma abordagem materialista histórica da realidade, trazendo à baila, na pri- meira seção, o debate sobre o neoliberalismo como revés político do processo de mundialização do capital, o que marca a dinâmica econômica atual e traz contundentes reverberações na saúde global; a categoria complexo-médico-industrial/financeiro assume relevo na segunda seção, quando se demonstra como a pandemia serviu para a acumulação de capital nesse complexo; e a determinação social da saúde, que é a categoria basilar na terceira seção, com vistas aos fundamentos ontológicos da relação economia-saúde. Em cada uma das fases da concatenação desenvolvida, dialogamos com dados da realidade, forjados na dinâmica pandêmica, a fim de, com eles e para além deles, traçar um caminho de reconstrução da esfera mais imediata da relação aqui estudada, alcançando suas determinações mais radicais.

\section{INTERVENÇÃO ESTATAL DURAN- TE A PANDEMIA: constrangimento neoliberal?}

A fase contemporânea do capitalismo se expressa, no seu braço estatal, por meio de uma conformação neoliberal, especialmente sentida no âmbito da destruição de políticas sociais outrora implementadas, principalmente em países que vivenciaram o que se convencionou chamar de Welfare State. Cabe registrar que, nas nações de economia dependente, há um histórico de debilidade no âmbito das políticas sociais e, nessas circunstâncias, a dinâmica neoliberal radicalizou a tendência de destruição e ampliou a dependência (Fontes, 2010).

Teixeira (1998) aponta que a recuperação dos ideais liberais de inspiração jusnaturalista e da economia política clássica (notadamente o conceito de mão invisível de Adam Smith) emerge após a Segunda Guerra Mundial, em especial no plano teórico, com o grupo de Mont Pèlerin, mas foram novamente renovados ante a necessidade da crítica ao Welfare State. O representante mais emblemático dessa corrente foi Friedrich Hayek, contando-se também com nomes como 
Milton Friedman, Karl Popper, Michael Polanyi e Salvador de Madariaga. Hayek e seu grupo afirmavam que a origem da crise que se anunciava estava no poder que havia sido conferido ao movimento operário, corroendo as bases de acumulação capitalista com suas pressões reivindicativas por salários e com sua pressão parasitária para que o Estado promovesse distribuição de renda e serviços sociais de qualidade. Segundo os economistas, o equacionamento dessa questão estava na criação de um Estado forte que fosse capaz de fraturar a estrutura sindical e de controlar os gastos sociais. Os governos modernos deveriam conduzir o Estado para intervenções cujo horizonte fossem a estabilidade monetária, com responsabilidade fiscal, e a contenção dos gastos com proteção social e com políticas para a empregabilidade, até porque o desemprego seria, nessa corrente, um componente natural e necessário à dinâmica da livre concorrência e regulação dos salários (Teixeira, 1998).

Com efeito, o conjunto de medidas adotadas pelos governos neoliberais contribuiu para o alcance de algumas metas traçadas, pelo menos nos países de capitalismo avançado. Em que pese aos resultados incipientes - em termos capitalistas -na experiência chilena do início dos anos de 1970, as medidas de Margaret Thatcher na Inglaterra e de Ronald Reagan nos Estados Unidos obtiveram algum êxito no controle da inflação, derrotando o movimento sindical, aumentando a taxa de desemprego e seu poder de regulação sobre os salários e aprofundando o nível de desigualdade. Conquanto, apesar de todos esses êxitos, o objetivo primordial do neoliberalismo não foi alcançado, qual seja, a reanimação das altas taxas de crescimento estáveis, tal qual antes da crise da década de 1970. (Anderson, 1995)

Precisamos fazer a ressalva de que, avançando para uma crítica radical ao neoliberalismo, concordamos com Fontes (2010) quando a autora alerta que o Estado neoliberal não pode ser questionado a partir de uma fundamentação nostálgica em relação ao Welfare State, visto que suas contradições não são en- dógenas a uma fase específica do capitalismo, embora assumam uma roupagem particular. Uma crítica nostálgica, logo parcial e insuficiente, acaba sendo uma crítica à fase e não ao sistema, ignorando as mediações que fizeram do Welfare State importante (funcional) para os anos dourados do capitalismo.

Para Anderson (1995), a desregulamentação financeira, amplamente defendida pelo programa neoliberal, criou condições muito mais férteis para a inversão especulativa do que para a recuperação do capital produtivo. Nesse ínterim, houve uma explosão dos mercados internacionais de câmbio, com transações que diminuíram o comércio mundial de mercadorias reais, metamorfoseando-se em trocas ilusórias na esfera financeira. Este argumento é importante para se pensar o neoliberalismo além da esfera política ou, mais especificamente, estatal, e entendê-lo como componente eminente da dinâmica de expansão da economia capitalista, a partir da qual, articuladas mundialmente desde meados da década de 1970, pressupõe-se novas respostas às suas idiossincrasias. A esse fenômeno, Chesnais (2001) denominou mundialização do capital, uma vez que considera a natureza expansiva e destruidora de limites inerentes à produção e reprodução do capital. Trata-se de uma universalização da dinâmica capitalista dentro de uma unidade heterogênea, especialmente marcada pela hierarquização das nações que compõem essa estrutura mundial.

Mészáros (2009, p. 796) investiga as determinações mais profundas dessa dinâmica, localizando-as no bojo das respostas do capital a uma crise sem precedentes, porque crônica, global e "rastejante", ainda que conserve em seu interior momentos cíclicos ou de disrupção. Nos termos do autor, trata-se de uma "crise estrutural" do capital, resultado dos constantes "deslocamentos" das contradições capitalistas a fim de conter a inexorável tendência de queda da taxa de lucros. Ante seus limites absolutos, o capital, por meio de suas personificações na economia mundial e no Es- 
tado, precisou dar respostas que superassem os obsoletos princípios rígidos do binômio taylorista/fordista na esfera produtiva, facilitasse a livre circulação do capital dentro dos Estados-nação e mundialmente, para o que se evocou o neoliberalismo, e acelerasse a rotação do capital com a fuga desde a esfera produtiva até a financeira, alimentando a ilusão de taxas de lucro crescentes a partir do fantástico mundo especulativo (Souza, 2019).

Nota-se que o neoliberalismo comparece enquanto um dos elementos-chave nesse processo de mundialização, na determinação reflexiva para com a reconfiguração produtiva (agora flexibilizada) e na hipertrofia da esfera financeira. Em especial, no que toca ao aspecto que este artigo busca problematizar, e em face da pandemia de COVID-19, destaca-se a tendência de amplificação dos saques que o capital financeiro realiza no fundo público das várias nações, sobremodo nas dependentes, mediante o artifício das dívidas públicas. $\mathrm{O}$ resultado disso é um conjunto de políticas sociais subfinanciadas e à míngua, determinando um contexto social limítrofe, no qual a pandemia do novo coronavírus fez transbordar uma série de fragilidades.

O caso brasileiro exemplifica bem esse histórico de subfinanciamento das políticas sociais, cujas causas estão localizadas, sobretudo, e conforme Salvador (2008), no mecanismo de Desvinculação de Receitas da União (DRU), usurpando-se anualmente cerca de $20 \%$ do Orনี çamento da Seguridade Social (OSS) ao longo ๙ dos anos 2000, sob o subterfúgio de gerar superavit primário para, no final das contas, amortizar juros da dívida pública. Para se ter uma ideia, de 1995 a 2012 foram desvinculados R\$ ¿ 578 bilhões do OSS para o orçamento fiscal கే (Mendes, 2013). Em 2013, a desvinculação foi

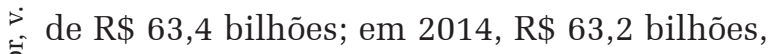
e a partir de 2016 foi aprovada sua ampliação para 30\% do OSS. (Souza, 2019)

Portanto, a tendência neoliberal se apresenta com intensidade no sentido de fragilizar as políticas sociais, de modo a atuar complementando o modus operandi do capitalismo contemporâneo. Por vezes, a tendência encontra seus próprios pontos de disrupção quando evidencia o seu caráter contraditório. Assim, argumenta-se que a pandemia da COVID-19 é um desses pontos, talvez o mais emblemático em face da crise estrutural, porquanto tenha demandado intervenções estatais que, a princípio, escapam à normalidade da tendência. Em meio à abrupta mudança na dinâmica cotidiana, com as medidas de prevenção da infecção pelo novo coronavírus e os reflexos econômico-sociais, os Estados-nação, tipicamente neoliberais, viram-se diante da necessidade de intervir, isto é, destinar orçamento, na saúde pública, na previdência e na assistência social. Até dezembro de 2020, 151 países introduziram medidas de proteção social ou reformularam programas pré-existentes. Cerca de $60 \%$ dessas medidas se situa no campo da assistência social, sobretudo com mecanismos de transferência de renda (cerca de um terço das medidas implementadas). Em média, os auxílios ou benefícios sociais duraram 2,9 meses, mas, em muitos casos, foram com pagamento único. No seu conjunto, os mecanismos de transferência de renda criados ou reformulados ante a COVID-19 representam um aumento de 86,6\% dos níveis de investimento pré-pandemia (Gentilini; Almenfi; Orton; Dale, 2020).

A título de exemplo, pode-se tomar o caso de alguns países: nos EUA, implantou-se o benefício de $\$ 1.200$ para adultos e $\$ 500$ para crianças; na Itália o auxílio variou de 400 a 800 euros por mês; na França, famílias já inseridas em outros programas sociais receberam um auxílio adicional de 150 euros, acrescido de 100 euros para cada criança; no Canadá, o suporte foi de $\$ 2.000$ por quatro meses; e, no Brasil, o auxílio emergencial foi de $\mathrm{R} \$ 600$ por três meses, com um adicional posterior que poderia chegar até R\$1.200, dividido em quatro parcelas. (Gentili et al., 2020) Amitrano, Magalhães e Silva (2020) mostram que países que não possuíam sistemas de seguridade social bem estruturados tiveram que gastar proporcionalmente mais com saúde e proteção social du- 
rante a pandemia. Os autores mostram dados que apontam a proporção do gasto com saúde diante do gasto total em medidas de enfrentamento da pandemia, revelando que os EUA investiram $14,0 \%$ com saúde e $24,8 \%$ com benefícios à população, ao passo que o Reino Unido investiu $1,2 \%$ e $3,4 \%$ e a França, $1,2 \%$ e $2,6 \%$ nas mesmas áreas, respectivamente. Portanto, "nos Estados Unidos [expoente neoliberal], a pouca estruturação do Welfare [no sentido de políticas sociais consistentes] faz com que haja a necessidade de criar novas estruturas e instituições e alocar mais recursos às já existentes, sobrecarregando essa parte do programa" (Amitrano; Magalhães; Silva, 2020, p. 18).

Essas ações fora da tendência predominante parecem demonstrar o constrangimento dos Estados neoliberais em darem um passo atrás. Contudo, para que este seja real, seria preciso que o neoliberalismo se sustentasse sobre outra ética, se é que nele há alguma. Para Teixeira (1998, p. 248), "a liberdade de mercado como condição necessária para a realização da liberdade humana é, na verdade, condição para sua desrealização, para sua não efetivação. A dimensão ética da economia, que a razão filosófica demonstra, não poderá se realizar enquanto o mercado permanecer como instância central da sociabilidade”. Para Lessa (2005), o complexo da ética é incompatível com o capital, uma vez que sua plena efetivação depende da emancipação humana. Portanto, em vez de um capitalismo constrangido na sua face neoliberal, há uma tentativa de remediar contradições que são inerentes ao sistema, a fim de manter a roda girando, mesmo que de forma claudicante.

\section{ACUMULAÇÃO E ESPECULAÇÃO A PARTIR DO COMPLEXO MÉDI- CO-INDUSTRIAL/FINANCEIRO}

O debate sobre o complexo médico-industrial possui origem anglo-saxã, com possível influência do debate sobre o complexo militar-industrial e de correntes que atrelam o desenvolvimento técnico-científico a tal complexo, sem necessariamente tecer críticas aos seus valores subjacentes. Todavia, na América Latina, em especial no Brasil, o debate ganhou as conotações que o fizeram ser uma das frentes investigativas mais frequentes da tradição marxista no âmbito da Saúde Coletiva (Mendonça; Camargo Jr., 2012). O auge do debate foi na década de 1980, com autores como Cordeiro (1980) e Oliveira e Fleury (1986), direcionado à investigação sobre a saúde como mediação para o acúmulo de capital por setores especializados da indústria, como o farmacêutico ou o de produção de artigos hospitalares. Em geral, essa categoria era o centro da crítica à mercadorização da saúde e da defesa de sistemas públicos, a exemplo do Sistema Único de Saúde (SUS), no Brasil.

Com a mundialização do capital tornando universais a reconfiguração produtiva, o neoliberalismo e a financeirização da economia, rapidamente o capital circulante nas indústrias ou nos serviços vinculados à saúde passou a ser objeto de especulação financeira, o que resultou na formulação, na década de 1990, da categoria complexo médico-financeiro para explicar como a saúde, nos moldes capitalistas, contribui para o aceleramento da rotação do capital (Vianna, 2002). Desse modo, Vianna (2002) esclarece que, a princípio, há uma concorrência entre os dois complexos, o que faz parte da dinâmica intrínseca do capitalismo. É possível dizer que se tratou de um período de adaptação, logo superado pelo domínio do capital financeiro no âmbito da reprodução capitalista, haja vista as reverberações da crise estrutural. Em pouco tempo, ocorreu o imbricamento dos dois complexos, expresso sobretudo pela abertura do capital industrial à especulação.

Mundialmente, organismos financeiros como o Banco Mundial (BM) e o FMI conduziram a financeirização, viabilizada pelas tendências neoliberais nos vários Estados-nação. No caso brasileiro, Souza (2019) destaca que: 
[...] três documentos [do BM] são marcantes do início desse processo: 'Brasil, novo desafio à saúde do adulto', no qual se direcionam as ações para a saúde do adulto de forma focalizada, através de uma atenção primária precarizada e criando as condições necessárias para o complexo médico-industrial-financeiro expandir por meio da média e alta complexidade; o 'Relatório sobre o Desenvolvimento Mundial de 1993: investindo em saúde', no qual se enfatiza a lógica custo-efetividade, defendendo um sistema que ofereça alguns serviços essenciais para os mais pobres e que possua, nos demais serviços, uma articulação com o setor privado; e 'A organização, prestação e financiamento da saúde no Brasil: uma agenda para os anos 90', quando são ratificadas as preocupações fiscais com a proposta de saúde prevista da CF de 1988 (p. 74-75).

Foi um processo progressivo, embora não livre de tensões, cuja manifestação mais evidente é o subfinanciamento dos sistemas públicos de saúde e a ascensão dos planos e seguros, viabilizando a

[...] conformação de um subsistema (ou mesmo de um sistema paralelo) privado de organização dos serviços de saúde que tem apresentado um elevado potencial de crescimento [...] calcado, de um lado, na atuação competitiva de empresas operadoras de planos e seguros de saúde, envolvendo modalidades de autogestão, medicina de grupo, cooperativas médicas e seguradoras, e, de outro lado, na atuação regulatória do Estado, mediante a atuação da Agência Nacional de Saúde Suplementar (lei 9.656 de 1998) [...] (Gadelha, 2003, p. 527-528).

Em relação ao financiamento do SUS, $\vec{\nabla}$ constata-se que sempre esteve aquém dos 10\% ․ do PIB nacional pretendidos para investimen을 to anual, uma vez que o valor tem orbitado em torno de 4\% e, até 2011, 2 a 3\% (Souza, 2019). - Agravando a conjuntura, outras políticas soc. ciais brasileiras com importância no processo + de determinação social da saúde vêm em ten$\therefore$ dência decrescente de financiamento, como constatou Vieira (2020) para os casos das políticas de saneamento, desenvolvimento agrário, ت habitação e urbanismo. Para a autora:

O quadro recente de financiamento das políticas sociais setoriais no Brasil sinaliza para maiores dificuldades na obtenção de progressos nas condições de vida e de trabalho da população e, mais do que isso, aponta para elevado risco de retrocesso nesses âmbitos, com impactos negativos sobre a situação de saúde dos brasileiros (Vieira, 2020, p. 958).

É possível afirmar que a fragilização dos sistemas de saúde foi, certamente, um obstáculo ao enfrentamento da pandemia no tempo e com a pujança que a conjuntura pedia. Seus efeitos, em especial para a força de trabalho do setor de saúde, foram sentidos por meio do alto índice de contaminação e morte de trabalhadores por COVID-19, da sobrecarga de trabalho, da falta de Equipamentos de Proteção Individual (EPI) e de outras medidas protetivas (Choi; Skrine-Jeffers; Cynthia-Logsdon, 2020). Observa-se que, na conjuntura da pandemia, ficou explícita a precariedade dos sistemas públicos de saúde e, ao mesmo tempo, pôde-se constatar que o complexo médico industrial/financeiro continuou expandindo seus níveis de acumulação e especulação de capital. Um dos desempenhos mais altos no Índice Ibovespa, em março de 2020, foi o da Raia Drogasil, do comércio farmacêutico, com alta de 10\%. Entre as 10 empresas que mais se valorizaram no primeiro trimestre de 2020, quatro têm relação direta com a saúde: Koken (58,80\%), Ping An Good Doctor (31,00\%), BGI (28,80\%), Gilead Sciences (23,55\%) (Moura, 2020).

Podemos afirmar que a primeira fase de enfrentamento da pandemia se constituiu em torno das medidas de proteção, impulsionando a utilização de insumos médico-hospitalares, em especial os EPI, mas também medicamentos utilizados na terapia intensiva, respiradores mecânicos e congêneres. Diante disso, é possível entender o crescimento de empresas ligadas à produção desses insumos. Com o avanço da pandemia, a pedra de toque passou a ser a corrida pela descoberta e fabricação da vacina, refletindo-se em forte especulação financeira e valorização dos laboratórios que se inseriram nessa corrida, sobretudo no segundo semestre de 2020. Alguns laboratórios chegaram a valorizações "vertiginosas", como a Novavax, com alta de $3.100 \%$, ou a Moderna, valorizada em 
$846 \%$. Mesmo os laboratórios que menos se valorizaram nessa corrida chegaram próximos de $100 \%$, como no caso da CureVac, com 90\% ao final de 2020 (Loureiro; Vitorio, 2021).

Note-se que os níveis de lucros das empresas, sejam indústrias, sejam do setor de serviços, é ditado pela sua valorização no mercado financeiro, o que revela um processo de imbricamento que explica a existência de um complexo ampliado, o médico-industrial/ financeiro. A pandemia da COVID-19 comparece como componente de relevo na relação economia-saúde, que há tempos se nutre do adoecimento humano. Começamos a constatar, assim, que a referida relação possui determinações recíprocas entre seus polos constituintes, conforme aprofundamos a seguir.

\section{A PRIORIDADE ONTOLÓGICA NA RELAÇÃO ECONOMIA-SAÚDE}

$\mathrm{O}$ argumento de que a pandemia da COVID-19 gera desemprego, miséria, fome e, em decorrência disso, doenças e mortes, vale-se apenas de um fragmento da realidade analisada. É verdade que a pandemia contribuiu para o agravamento dessas questões, mas essa narrativa parcelar parece ignorar que existe uma dinâmica econômica anterior que, por sua própria natureza, gera desigualdade social e todos os problemas dela decorrentes. A história do capitalismo é de uma radical desigualdade social, embora se produza riqueza sem precedente. Resgatando um histórico recente, Piketty (2013) demonstra que, entre 1987 e 2013, o número de bilionários (em dólares) aumentou 10 vezes (de 140 indivíduos adultos para 1.400) e sua riqueza aumentou 18 vezes (de 300 bilhões para 5.4 trilhões de dólares). Acrescenta que as maiores riquezas tiveram um crescimento anual de 6 a $7 \%$, enquanto a riqueza média mundial cresceu apenas $2,1 \%$, sendo um indicativo de aumento da concentração de riqueza.

De acordo com dados de 2018, os mais ricos representam $0,8 \%$ da população mundial, mas acumulam $44,8 \%$ da riqueza do mundo (cerca de 142 trilhões de dólares). Isso representa uma riqueza 23,7 vezes maior do que os $70 \%$ da população que está na base da pirâmide, uma vez que esse segmento possui $1,95 \%$ da riqueza mundial (6,2 trilhões de dólares) (Credit Suisse, 2018). Já sobre o desemprego, dados do Banco Mundial revelam que a taxa de desemprego global em 2019 já foi levemente maior que 2018, uma vez que se registrou, respectivamente, 5,372\% e 5,373\%, revertendo uma tendência que era de queda desde 2009 (World Bank, 2021). ${ }^{3}$ Este dado, por si só demasiado, não leva em conta os cerca de 470 milhões de indivíduos subempregados ou que deixaram de procurar emprego em 2019, o que revela que a dimensão do problema é ainda maior, uma vez que, muitas vezes, mascara-se a taxa de desemprego, gerando séries históricas de queda da taxa de desemprego (Presse, 2020).

Trata-se de uma dinâmica social desigual desde suas raízes, como Marx (1988) demonstrou. Para o pensador alemão, existe uma lei geral (no sentido de tendência) da acumulação capitalista, a partir da qual o processo de produção gera riqueza ao mesmo tempo que pauperiza os produtores desta riqueza (o proletariado). Nesse sentido, a relação entre capital constante (valor dos meios de produção) e capital variável (valor da força de trabalho) precisa assumir uma composição orgânica de aumento relativo de capital constante perante o capital variável, de onde se origina o exército industrial de reserva e, portanto, o desemprego estrutural e o pauperismo absoluto. É claro, esse aumento relativo não implica a impossibilidade do aumento do capital variável em termos absolutos, até porque, conforme o próprio Marx (1988), não há produção de valor sem a força de trabalho. Para Souza, Silva e Silva (2013), a saúde consiste em um processo social no qual há um entrelaçamento de várias expressões da questão social, a saber: pobreza, aquilo que já era grave, é retroalimentado pela pandemia, tornando-se trágico (WORLD BANK, 2021). 
desemprego, violência, destruição ambiental etc. Para os autores, no âmago dessa trama está a lei geral da acumulação capitalista, enquanto uma determinação essencial de um processo socialmente construído. Isto é,

[...] enquanto existir a lei geral da acumulação capitalista existirá a 'questão social' e seus desdobramentos para saúde. E essa condição, imposta para atender aos interesses da classe exploradora, é que consiste na determinação essencial para o processo saúde-doença, enquanto um fenômeno estudado para além dos aspectos biológicos e que só pode ser superado em uma outra forma de sociabilidade (Souza; Silva; Silva, 2013, p. 56).

A tese de determinação essencial não exclui outros níveis de determinação, embora os conceba a partir da ideia de unidade heterogênea. No interior de uma espiral dialética, repleta de reflexões e refrações, podemos afirmar que a prioridade ontológica no processo de determinação da saúde está na dinâmica econômica, aqui entendida para além de um conjunto de operações produtivas ou financeiras, mas no sentido lukacsiano do complexo do trabalho. Ou seja, não se trata de uma relação mecânica, mas de uma relação de mútuas e variadas determinações, sendo que um complexo comparece com prioridade na estrutura qualitativa do ser social. Nessa perspectiva, a saúde equivale a uma particularidade do ser social e, portanto, assim como a universalidade dessa esfera de ser, reflete as relações seminais do $\vec{\nabla}$ complexo do trabalho. Em uma sociedade so$\underset{\sim}{\sim}$ erguida a partir de relações desiguais de traba$\stackrel{2}{\sigma}$ lho, a saúde acaba por expressar, majoritaria\% mente, tal caráter (Souza, 2020a).

Com a pandemia do novo coronavírus, essa relação espiralada fica evidenciada, bem como surgem as narrativas pós-modernas que localizam na pandemia a causa da tragédia social que se segue, mas sem observar a natureza intrinsecamente trágica e contraditória do sistema do capital, assim como seus reflexos sobre a saúde em geral. Por conseguinte, para além do novo coronavírus, a trama causal da pandemia envolve: a) as alterações ambientais advindas da transformação da natureza em capital; b) o trânsito rápido e de largo alcance de pessoas e objetos pelo mundo, enquanto reflexo da mundialização do capital; c) o processo de fragilização das políticas sociais, em especial de saúde, corolário à neoliberalização do Estado; d) o fomento de uma cultura fugaz tal qual as relações sociais de produção, quando em geral se vê a disseminação de informações fora do contexto ou nas quais a narrativa prevalece sobre o fato, o que tem atrapalhado o conhecimento sobre uma doença nova; e) o processo de individuação soerguido da natureza concorrencial do capitalismo e suas reverberações na relativização do distanciamento social; f) as condições desfavoráveis de indivíduos e famílias para a adoção de medidas preventivas, pois, antes mesmo da pandemia, já estavam imersos no pauperismo; entre outros elementos nos quais se percebe não só uma relação direta ou indireta com a pandemia, mas também com raízes em uma dinâmica econômica que lhe antecede (Souza, 2020b).

Com efeito, compreender a determinação social da saúde e sua unificação (heterogênea) a partir da mundialização do capital se faz peremptório na análise da relação economia-saúde, bem como suas contradições e rebatimentos mútuos. Portanto, as particularidades da pandemia da COVID-19, ainda que lhe confiram caráter atípico, revelam, também, um processo subjacente que contém conexões com uma espiral histórica, com prioridade ontológica da economia no seu processo de determinação.

\section{CONSIDERAÇÕES FINAIS}

A espiral economia-saúde revela várias facetas, a depender do ângulo de análise. Pode-se observar os efeitos da mundialização do capital (com o neoliberalismo) sobre os sistemas de saúde pública, o processo de acumulação e especulação a partir do complexo médico-industrial/financeiro ou uma relação mais universal, na qual a lei geral de acumulação 
comparece na base da determinação social da saúde em geral, por gerar desigualdade social. Apenas em um recorte muito particular e fora do processo histórico é que faz sentido a relação linear na qual a pandemia da COVID-19 é a responsável pela tragédia econômico-social que, equacionada, voltará a beneficiar a saúde. Aqui, demonstramos que, não obstante os efeitos da pandemia do novo coronavírus, assim como qualquer questão sanitária, retroalimentarem a espiral, existe uma base econômica que exerce prioridade ontológica, sem que isso represente mecanicismo ou determinismo.

A dinâmica econômica da sociedade capitalista é desigual e destruidora por si só, e a recuperação do seu crescimento através da fantasia financeira apenas pode produzir mais desigualdade, doença e morte. A prioridade ontológica que explicitamos aqui, porque subsumida a determinados interesses capitalistas, expressa-se na prioridade prática a qual alguns líderes de Estado manifestaram ao quererem salvar suas economias, ainda que isso custasse vidas. A nosso ver, a prioridade ontológica que demonstramos revela uma necessidade prática inversa, ou seja, salvar vidas independentemente da economia, o que requer, inclusive, em um horizonte histórico, a transformação radical das bases econômicas da sociedade.

Recebido para publicação em 20 de março de 2020 Aceito em 6 de julho de 2021

\section{REFERÊNCIAS}

AMITRANO, C.; MAGALHÃES, L. C. G.; SILVA, M. S. Medidas de enfrentamento dos efeitos econômicos do pandemia COVID-19: panorama internacional e análise dos casos dos Estados Unidos, do Reino Unido e da Espanha. Brasília, DF: Ipea, 2020.

ANDERSON, P. Balanco do neoliberalismo. In: SARDER, E.; PABLO, G. (org.). Pós-neoliberalismo: as políticas sociais e o Estado democrático. Rio de Janeiro: Paz e Terra, 1995. p. 9-23

CHESNAIS, F. Mundialização: o capital financeiro no comando. Outubro, v. 5, p. 7-28, 2001.

CHOI, K. R.; CYNTHIA-LOGSDON, M.; SKRINE-JEFFERS, $K$. Nursing and the novel coronavirus: Risks and responsibilities in a global outbreak. Journal of Advanced Nursing, Oxford, v. 76, n. 7, p. 1-2.
CORDEIRO, H. A indústria da saúde no Brasil. Rio de Janeiro: Graal, 1980.

CREDIT SUISSE. Global wealth report 2018: US and China in the lead. Zurich: Credit Suisse Research Institute, 2018.

FONTES, V. O Brasil e o capital imperialismo: teoria e história. 2. ed. Rio de Janeiro: EPSJV, UFRJ, 2010

GADELHA, C. A. G. O complexo industrial da saúde e a necessidade de um enfoque dinâmico na economia da saúde. Ciência \& Saúde Coletiva, Rio de Janeiro, v. 8, n. 2 , p. 521-535, 2003.

GENTILINI, U.; ALMENFI, M.; ORTON, I.; DALE, P. Social Protection and Jobs Responses to COVID-19: a real-time review of country measures. v. 14. Washington: World Bank, 2020. Disponível em: https://openknowledge.worldbank. org/handle/10986/33635. Acesso em: 8 abr. 2021.

INTERNATIONAL MONETARY FUND. World economic outlook update, January 2021. Washington, DC: IMF Disponível em: https://www.imf.org/en/Publications/WEO/ Issues/2021/01/26/2021-world-economic-outlook-update. Acesso em: 8 abr. 2021.

LESSA, S. Ética, política e serviço social. Katálysis, Florianópolis, v. 8, n.2, p. 256-266, 2005.

LOUREIRO, R; VITORIO, T. Busca pela vacina fez laboratórios ganharem bilhões durante a pandemia. Exame, São Paulo, 14 dez. 2020. Disponível em: https://exame. com/ciencia/busca-pela-vacina-fez-laboratorios-ganharembilhoes-durante-a-pandemia/. Acesso em: 8 abr. 2021

MARX, K. O Capital: crítica da economia política. Livro primeiro, Tomo II. 3. ed. São Paulo: Nova Cultural, 1988.

MENDES, A. The long battle for SUS funding. Saúde e Sociedade, São Paulo, v. 22, n. 4, p. 987-993, 2013.

MENDONCA, A. L. O.; CAMARGO JR., K. R. Complexo médico-industrial/financeiro: os lados epistemológico e axiológico da balança. Physis - Revista de Saúde Coletiva, Rio de Janeiro, v. 22, n. 1, p. 215-238, 2012.

MÉSZÁROS, I. Para além do Capital: rumo a uma teoria da transição. São Paulo: Boitempo, 2009.

MOURA, J. Entenda como o coronavírus afeta o mercado financeiro. Folha de S.Paulo, São Paulo, 8 mar. 2020. Disponível em: https://www1.folha.uol.com.br/ mercado/2020/03/entenda-como-o-coronavirus-tem-afetadoo-mercado-financeiro.shtml. Acesso em: 30 mar. 2020.

OLIVEIRA, J. A. A.; FLEURY, S. M. (Im)Previdência Social? 60 anos de história da Previdência no Brasil. Rio de Janeiro: Abrasco, 1986.

PIKETTY, T. O capital no século XXI. Rio de Janeiro: Intrínseca, 2013.

PRESSE, F. Número de desempregados no mundo deve alcançar 190,5 milhões neste ano, diz OIT. G1, Rio de Janeiro, 20 jan. 2020. Disponível em: https://g1.globo.com/ economia/noticia/2020/01/20/numero-de-desempregadosno-mundo-deve-alcancar-1905-milhoes-neste-ano-diz-oit. ghtml. Acesso em: 10 abr. 2020.

SALVADOR, E. Fundo público no Brasil: Financiamento e destino dos recursos da seguridade social (2000 a 2007). 2008. Tese (Doutorado em Política Social) -Universidade de Brasília, Brasília, 2008.

SOUZA, D. O.; SILVA, S. E. V.; SILVA, N. O. Determinantes sociais da saúde: reflexões a partir das raízes da "questão social". Saúde e Sociedade, São Paulo, v. 22, n. 1, p. 44-56, 2013.

SOUZA, D. O. Financeirização, fundo público e os limites à universalidade da saúde. Saúde em debate, Rio de Janeiro, v. 43, n. spe. 5, p. 71-81, 2019.

O caráter ontológico da determinação social da saúde. Serviço Social \& Sociedade, São Paulo, n. 131, p. 174-191, 2020. 
A pandemia de COVID-19 para além das Ciências da Saúde: reflexões sobre sua determinação social. Ciência $\mathcal{E}$ Saúde Coletiva, Rio de Janeiro, v. 25, supl. 1, p. 24692477, 2020.

TEIXEIRA, J. S. F. O neoliberalismo em debate. In: TEIXEIRA, J. P. F.; ALVES, G.; NETO, J. M.; OLIVEIRA, M. A. (org.). Neoliberalismo e reestruturação produtiva: as novas determinações do mundo do trabalho. 2. ed. São Paulo: Cortez, 1998. p. 195-252.

VIANNA, C. Estruturas do sistema de saúde: do complexo médico-industrial ao médico-financeiro. Physis - Revista de Saúde Coletiva, Rio de Janeiro, v. 12, n. 2, p. 375-390, 2002.
VIEIRA, F. S. Gasto federal com políticas sociais e os determinantes sociais da saúde: para onde caminhamos? Saúde em Debate, Rio de Janeiro, v. 44, n. 127, p. 947-961, 2020.

WORLD BANK. Unemployment, total (\% of total labor force) (modeled ILO estimate). Washington, DC, 2021. Disponível em: https://data.worldbank.org/indicator/ SL.UEM.TOTL.ZS?view= chart. Acesso em: 9 abr. 2021.

WORLD HEALTH ORGANIZATION (WHO). Weekly epidemiological update - 27 January 2021. Genebra: WHO, 2021. Disponível em: https://www.who.int/publications/m/ item/weekly-epidemiological-update---27-january-2021. Acesso em: 21 fev. 2021. 


\section{COVID-19 PANDEMIC: lens to understand the economy-health spiral}

Diego de Oliveira Souza

This article discusses the economy-health relationship through the lens of the COVID-19 pandemic. Based on a historical materialistic approach to reality, we investigate the interfaces of such relationship using data from the pandemic period. It also addresses the impacts of the neoliberal process of globalization of capital on healthcare; the consolidation of the industrial/financial-medical complex and how it was nourished by the pandemic; and the process of social determination of health, which explains the ontologically constructed economy-health relationship, including the specificities of the pandemic. Such an approach refutes a linear understanding of the economyhealth relationship, revealing its spiral dynamics.

KeYwords: Coronavirus. Industrial/FinancialMedical Complex. Neoliberalism. Pandemics. Public Health.

\section{LA PANDEMIE DU COVID-19: un prisme pour comprendre la spirale économie-santé}

\author{
Diego de Oliveira Souza
}

Cet article traite de la relation économie-santé à travers le prisme de la pandémie du COVID-19. Basée sur une approche matérialiste historique de la réalité, nous discutons les interfaces de cette relation en utilisant les données de la période pandémique. Il aborde également les impacts du processus néolibérale de mondialisation du capital sur la santé ; la consolidation du complexe médicalindustriel/financier et la manière dont il a été nourrit par la pandémie ; et le processus de détermination sociale de la santé, qui explique la relation économie-santé ontologiquement construite, y compris les particularités de la pandémie. Une telle approche réfute une compréhension linéaire de la relation économie-santé, révélant sa dynamique en spirale.

Mots-clés: Coronavirus. Complexe MédicalIndustriel/Financier. Néolibéralisme. Pandémies. Santé Publique. 
